\title{
High incidence of Plasmodium knowlesi malaria compared to other human malaria species in several hospitals in Malaysia
}

\author{
Lai, M.Y. ${ }^{1}$, Rafieqin, N. ${ }^{1}$, Lee, P.Y.@Lee, Z. ${ }^{1}$, Amir Rawa, M.S. ${ }^{1}$, Dzul, S. ${ }^{1}$, Yahaya, N. ${ }^{2}$, Abdullah, F.H. ${ }^{3}$, \\ Othman, N. ${ }^{4}$, Jelip, J. ${ }^{5}$, Ooi, C.H. ${ }^{6}$, Ibrahim, J. ${ }^{6}$, Aung, M. ${ }^{7}$, Abdullah, A.H. ${ }^{7}$, Laili, $^{2}{ }^{8}$, Lau, Y.L. ${ }^{*}$
}

${ }^{1}$ Department of Parasitology, Faculty of Medicine, University of Malaya, 50603 Kuala Lumpur, Malaysia

2Jabatan Kesihatan Negeri Pulau Pinang, 10590 Pulau Pinang, Malaysia

${ }^{3}$ Pusat Penyelidikan Klinikal, Hospital Sultanah Nur Zahirah, 20400 Kuala Terengganu, Malaysia

${ }^{4}$ Microbiology Unit, Department of Pathology, Hospital Sultanah Nur Zahirah, Jalan Sultan Mahmud, 20400 Kuala Terengganu, Malaysia

${ }^{5}$ Ministry of Health Malaysia, 62590 Putrajaya, Malaysia

${ }^{6}$ Sarawak State Health Department, 03050 Kuching, Sarawak

${ }^{7}$ Hospital Kuala Lipis, 27200 Kuala Lipis, Pahang

${ }^{8}$ Hospital Raja Permaisuri Bainun, 30450 Ipoh, Perak

*Corresponding author: lauyeeling@um.edu.my

\section{ARTICLE HISTORY}

Received: 25 February 2021

Revised: 10 June 2021

Accepted: 10 June 2021

Published: 31 July 2021

\begin{abstract}
Through the regional control programme, Malaysia has been successfully reducing the incidence of Plasmodium falciparum and Plasmodium vivax infections. However, the incidence of zoonotic malaria Plasmodium knowlesi infection is increasing and now has been the major cause of malaria in Malaysia especially Malaysian Borneo. The emergence of knowlesi infection has threatened the malaria elimination programme which the government aims to reduce the overall malaria infections by 2020. Unlike other benign human Plasmodium spp., $P$. knowlesi can cause fatal infections. The aim of this study was to determine the incidence and distribution of five human malaria parasites including $P$. knowlesi in Peninsular Malaysia and Malaysian Borneo. A total of 112 blood samples were collected from seven states and district hospitals in Peninsular Malaysia and Malaysian Borneo from year 2015 to 2016. The samples were examined by microscopy and further confirmed by nested PCR assay targeting $18 \mathrm{~S}$ rRNA gene of Plasmodium spp. Following the nested PCR assays, a total of 54 $(48.2 \%)$ samples were positive for $P$. knowlesi infections, $12(10.7 \%)$ cases were positive for $P$. vivax infections, followed by $7(6.3 \%)$ cases of $P$. falciparum and $4(3.5 \%)$ cases of $P$. malariae. There were 3 cases $(2.7 \%)$ of mixed infections (P. knowlesi/P. vivax). However, no cases were identified as $P$. ovale. A total of $32(28.6 \%)$ cases were found as negative infections. LoopMediated Isothermal Amplification Assay (LAMP) was performed to confirm inconclusive results produced by microscopy and nested PCR. P. knowlesi showed the highest prevalence in Sarawak $(n=30)$, Sabah $(n=13)$, Pulau Pinang $(n=5)$ and Pahang $(n=6)$. PCR and LAMP was not able to detect a large number of microscopy positive samples due to DNA degradation during storage and shipping. Among all the states involved in this study, the highest prevalence of $P$. knowlesi infection was found in Sabah and Sarawak.
\end{abstract}

Keywords: Malaria; P. knowlesi; PCR; molecular diagnostic; LAMP.

\section{INTRODUCTION}

Malaria is one of the alarming vector-borne diseases, transmitted via the bite of female mosquitoes belonging to the genus of Anopheles and currently affecting 219 million people worldwide with 435000 death cases as of 2017 (Pimenta et al., 2015; World Health Organization, 2018). Conventionally, only four species of the causative agent for malaria are medically important: Plasmodium falciparum, Plasmodium malariae, Plasmodium vivax, and Plasmodium ovale. Nevertheless, there is a rise of malaria cases due to fifth species that is pathogenic to human, Plasmodium knowlesi, among Southeast Asia's countries (Alemu et al., 2013; Singh et al., 2004). Plasmodium knowlesi is initially a simian malarial parasite which later on was discovered to be a potent contributor to malaria cases in Malaysia, accounting for $50 \%$ of malaria cases in Sarawak (Foster et al., 2014). The occurrence of malaria infections is associated with farming and deforestation activities. Malaysia harbours abundant of rainforests which are the possible conduit to the highest rate of malaria cases among aboriginal (Orang asli) minority group and soldiers (Koh et al., 2004; Jamaiah et al., 2005). 
Immigration of undocumented migrant workers from countries that are endemic for malaria infection is one of the conduits for malaria transmission and re-introduction of malaria in Malaysia (Jeffree et al., 2018). Besides, hot climate and humidity further facilitate the transmission of malaria (Rahman et al., 1997). Malaria infections is primarily impacting poor and rural populations. Various interventional malaria control programs and activities have been conducted and the reduction in the cases of malaria was notifiable until the year of 2004 as the cases of $P$. knowlesi infections were reported. Despite of the first malaria case by $P$. knowlesi was reported from Peninsular Malaysia dated back in 1965, it is no later than the early 2000s that a large focus of human knowlesi infection occurred in Kapit, Sarawak (Chin et al., 1965; Singh \& Daneshvar, 2010). Since then, a greater number of malaria cases has been reported from Malaysia and $P$. knowlesi is the main cause of malaria. The incidence of $P$. malariae/P. knowlesi infections in Sabah was increased by more than 10-fold between 2004 and 2011 rendering significant increment of 59 cases to 703 cases (William et al., 2013). P. knowlesi appears to be the most common Plasmodium spp. in Malaysian Borneo (Sabah and Sarawak) while Pahang has been recognised as the highest contributor of human knowlesi malaria cases in Peninsular Malaysia between September 2012 and December 2013 (Yusof et al., 2014). $P$. vivax was observed to be the predominant causative agent of malaria in Selangor (Vythilingam et al., 2008).

To track the number of malaria cases in Malaysia, this study aims to elucidate the geographical distribution of malaria cases across several hospitals in Malaysia from August 2015 until June 2016 and a prospective malaria surveillance study.

\section{MATERIALS AND METHODS}

\section{Sample collections}

A total of 112 samples were collected from year 2015 to 2016. The samples were collected from states and district hospitals in Peninsular Malaysia (Kuala Lumpur, Perak, Pahang, Pulau Pinang and Terengganu) and Malaysia Borneo (Sabah and Sarawak). These samples were collected from malaria infected patients. This ethical approval for this study was obtained from the Medical Ethics Committee of UMMC (reference number: 817.18) and Medical Research Ethics Committee (MREC) (reference number NMRR-12-949-11328).
Informed verbal consents were obtained during the blood collections.

\section{Microscopy}

Thin films were prepared according to Giemsa's staining and thick films were prepared by Field's staining (Warhurst \& Williams, 1996). Slides were air dried and examined by experienced microscopists to identify the malaria parasites. Parasitemia was calculated either per 1,000 erythrocytes in the thin film at low parasitemia or per 200 white blood cells in the thick film. The slide was considered as negative if no parasites were seen in at least 100 high-power fields. DNA templates were extracted from the collected blood samples by using DNeasy Blood and Tissue Kit following the manufacturer's protocol (Qiagen, Hilden, Germany). The extracted DNA was served as the template for nested PCR.

\section{PCR amplification}

A nested PCR was performed for the malaria infected samples, which targets on Plasmodium small subunit ribosomal RNA (18S $r R N A$ ) gene. The primers used for the assay have been previously described by Snounou et al. (1993) and Imwong et al. (2009) (Table 1). Four $\mu \mathrm{L}$ of the extracted DNA was used as template. Nested 1 PCR was performed in a final volume of $25 \mu \mathrm{L}$ containing $1 \mathrm{X}$ of PCR buffer, $0.4 \mathrm{iM}$ of each primer (rPLU1 and rPLU5) (MyTACG Bioscience Enterprise, Malaysia), dNTPs mix $(200 \mu \mathrm{M}), \mathrm{MgCl}_{2}(4 \mathrm{mM})$ and Taq DNA polymerase (1U) (Promega Corporation, Madison, United States). Cycling parameter was consisted of denaturation at $94^{\circ} \mathrm{C}$ for $4 \mathrm{~min}$, followed by 35 cycles of $94^{\circ} \mathrm{C}$ for $30 \mathrm{~s}, 55^{\circ} \mathrm{C}$ for 1 $\min , 72^{\circ} \mathrm{C}$ for $1 \mathrm{~min}$ and a final extension at $72^{\circ} \mathrm{C}$ for $5 \mathrm{~min}$.

Nested 2 PCR amplification is a species identification PCR assay, which consisted of 5 PCR assays, targeted on $P$. knowlesi, P.ovale, P. vivax, P. falciparum and P. malariae. Four $\mu \mathrm{L}$ of nested 1 PCR product was used as the template for each of nested 2 PCR assays. The conditions and concentrations used in the nested 2 PCR amplifications were similar to those used in nested $1 \mathrm{PCR}$, except for the annealing temperature $\left(58^{\circ} \mathrm{C}\right)$ for species-specific primers (PkF1140/PkR1550, rOVA1/rOVA2, rVIV1/rVIV2, rFAL1/rFAL2 and $r M A L 1 / r M A L 2)$. The amplified products were sent to MyTACG Bioscience Enterprise for sequencing to validate the identities of the species. On top of that, Loop-Mediated Isothermal Amplification Assay (LAMP) was performed to confirm doubtful or inconclusive results produced by

Table 1. Sequences of primers used in this study

\begin{tabular}{|c|c|c|c|c|c|}
\hline Species & $\begin{array}{l}\text { Name of } \\
\text { primer }\end{array}$ & Sequences $\left(5^{\prime}-3^{\prime}\right)$ & $\begin{array}{c}\text { Annealing } \\
\text { temperature }\left({ }^{\circ} \mathrm{C}\right)\end{array}$ & $\begin{array}{l}\text { Product } \\
\text { size }(b p)\end{array}$ & References \\
\hline Plasmodium spp. & $\begin{array}{l}\text { rPLU1 } \\
\text { rPLU5 }\end{array}$ & $\begin{array}{l}\text { TCAAAGATTAAGCCATGCAAGTGA } \\
\text { CCTGTTGTTGCCTTAAACTCC }\end{array}$ & 55 & 1200 & Snounou et al., 1993 \\
\hline P. knowlesi & $\begin{array}{l}\text { PkF1140 } \\
\text { PkR1550 }\end{array}$ & $\begin{array}{l}\text { GATTCATCTATTAAAAATTTGCTTC } \\
\text { GAGTTCTAATCTCCGGAGAGAAAAGA }\end{array}$ & 58 & 410 & Imwong et al., 2009 \\
\hline P. ovale & $\begin{array}{l}\text { rOVAL1 } \\
\text { rOVAL2 }\end{array}$ & $\begin{array}{l}\text { ATCTCTTTTGCTATCTTTTTTTAATATTTGGAGA } \\
\text { GGAAAAGGACACATTAATTGTATCCTAGTG }\end{array}$ & 58 & $659-662$ & Snounou et al., 1993 \\
\hline P. vivax & $\begin{array}{l}\text { rVIV1 } \\
\text { rVIV2 }\end{array}$ & $\begin{array}{l}\text { CGCTTCTAGCTTAATCCACATAACTGATAC } \\
\text { ACTTCCAAGCCGAAGCAAAGAAAGTCCTTA }\end{array}$ & 68 & 121 & Snounou et al., 1993 \\
\hline P. falciparum & $\begin{array}{l}\text { rFAL1 } \\
\text { rFAL2 }\end{array}$ & $\begin{array}{l}\text { TTAAACTGGTTTGGGAAAACCAAATATATT } \\
\text { ACACAATGAACTCAATCATGACTACCCGTC }\end{array}$ & 58 & 206 & Snounou et al., 1993 \\
\hline P. malariae & $\begin{array}{l}\text { rMAL1 } \\
\text { rMAL2 }\end{array}$ & $\begin{array}{l}\text { ATAACATAGTTGTACGTTAAGAATAACCGC } \\
\text { AAAATTCCCATGCATAAAAAATTATACAAA }\end{array}$ & 58 & 145 & Snounou et al., 1993 \\
\hline
\end{tabular}


microscopy and nested PCR. LAMP was carried out according to the previous publication (Lau et al., 2016). The amplification was carried out in a Loopamp real-time turbidimeter (LA-320; Teramecs, Co., Ltd., Tochigi, Japan).

\section{RESULTS}

From the initial microscopy examination, 9, 60, 25, 6 and 11 samples were diagnosed as $P$. falciparum, P. knowlesi, P. vivax, $P$. malariae and mixed infections ( $P$. falciparum/P. vivax, $P$. knowlesi/P. falciparum and P. knowlesi/P. malariae), respectively (Table 2). Out of the 11 mixed infections, 1 sample was negative for malaria infection, 2 samples were screened as single infection for $P$. falciparum and 8 samples were positive for $P$. knowlesi using nested PCR. Nested PCR detected 15 additional $P$. knowlesi on top of the 39 detected by microscopy, apart from the 8 P. knowlesi/P. malariae mixed infections, 1 was initially diagnosed as $P$. falciparum, and 3 as $P$. vivax and $P$. malariae, respectively.
The samples were collected from district or states hospitals or clinics from Kuala Lumpur, Pahang, Perak, Pulau Pinang, Terengganu, Sabah and Sarawak throughout the study (Figure 1). By using the previously published primer sequences, the size of the amplicons generated by $P$. knowlesi, $P$. ovale, P. vivax, P. falciparum and P. malariae were $410 \mathrm{bp}$, 659662 bp, 121 bp, 206 bp and 145 bp, respectively (Figure not shown). Out of 112 samples, only 80 cases were positive for malaria infections following the nested PCR assays screening (Table 3). In Pulau Pinang, $P$. knowlesi, $P$. vivax and $P$. falciparum were responsible for $4.4 \%(n=5), 7 \%(n=8)$ and $3.5 \%(n=4)$, respectively. Meanwhile, in Perak, 1 case of $P$. malariae was recorded and it was the only one incidence $(0.9 \%)$ was recorded during the sample collection period. In Pahang, total of 6 cases $(5.3 \%)$ were found and all samples were positive for $P$. knowlesi. Meanwhile, out of 47 cases in Sarawak, 30 samples $(26.5 \%)$ were positive for $P$. knowlesi and the rest of the samples were negative for malaria. In Kuala Lumpur, $P$. vivax and P. falciparum responsible for $2.7 \%(n=3)$ and $1.8 \%$

Table 2. Detection of Plasmodium spp. by microscopy and PCR methods in malaria patients samples

\begin{tabular}{|c|c|c|c|c|c|c|c|c|c|c|}
\hline & \multicolumn{9}{|c|}{ Result of microscopy examination } & \multirow{2}{*}{ No. cases by $P C R$} \\
\hline & $P f$ & $P k$ & $P v$ & $P m$ & Po & $P k / P m$ & $P f / P v$ & $P k / P f$ & Negative & \\
\hline Pf & 4 & 0 & 1 & 0 & 0 & 1 & 1 & 0 & 0 & 7 \\
\hline$P k$ & 1 & 39 & 3 & 3 & 0 & 8 & 0 & 0 & 0 & 54 \\
\hline Pv & 1 & 1 & 9 & 0 & 0 & 0 & 0 & 0 & 1 & 12 \\
\hline Pm & 0 & 1 & 0 & 3 & 0 & 0 & 0 & 0 & 0 & 4 \\
\hline Po & 0 & 0 & 0 & 0 & 0 & 0 & 0 & 0 & 0 & 0 \\
\hline$P k / P v$ & 0 & 0 & 3 & 0 & 0 & 0 & 0 & 0 & 0 & 3 \\
\hline Negative & 3 & 19 & 9 & 0 & 0 & 0 & 0 & 1 & 0 & 32 \\
\hline Total & 9 & 60 & 25 & 6 & 0 & 9 & 1 & 1 & 1 & 112 \\
\hline
\end{tabular}

Pf: P. falciparum; Pk: P. knowlesi; Pv: P. vivax; Pm: P. malariae; Po: P. ovale.

\section{Peninsular Malaysia}

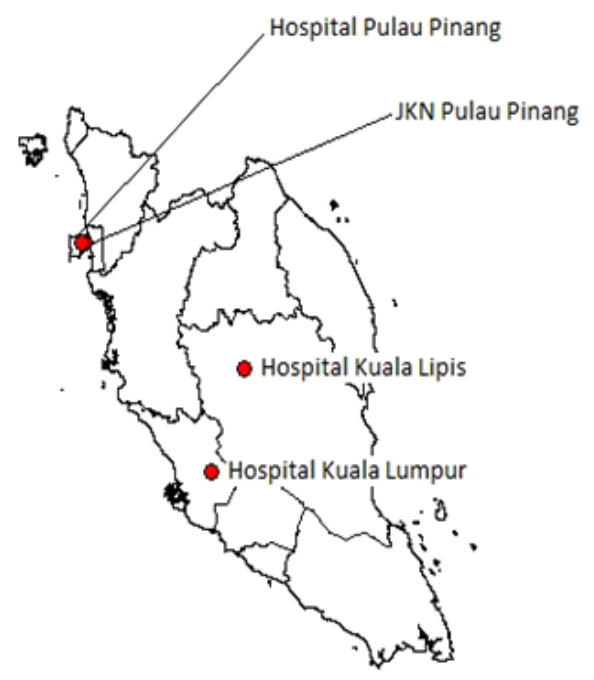

\section{East Malaysia}

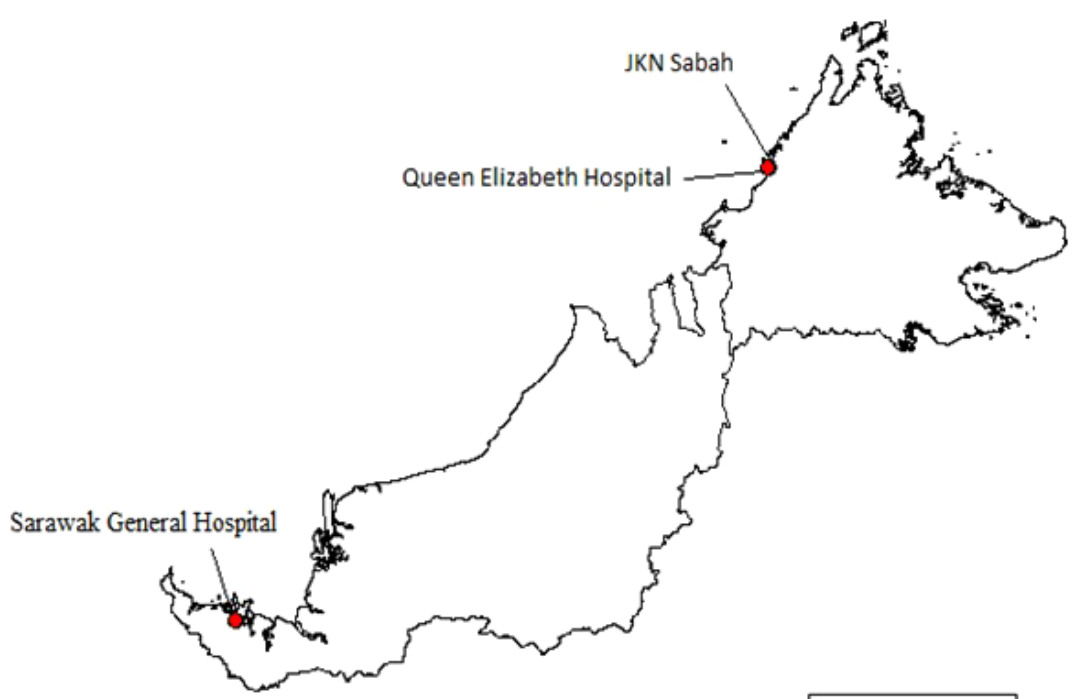

Study areas

Figure 1. Map of Malaysia showing the locations of study. 
Table 3. PCR-based species profile of malaria cases collected from areas in the present study

\begin{tabular}{|c|c|c|c|c|c|c|c|c|}
\hline State & P. falciparum & P. knowlesi & P. vivax & P. malariae & P. ovale & P. knowlesi/ P. vivax & Negative & Total \\
\hline Kuala Lumpur & 2 & 0 & 3 & 0 & 0 & 0 & 0 & 5 \\
\hline Pahang & 0 & 6 & 0 & 0 & 0 & 0 & 0 & 6 \\
\hline Perak & 0 & 0 & 0 & 1 & 0 & 0 & 0 & 1 \\
\hline Pulau Pinang & 4 & 5 & 8 & 0 & 0 & 3 & 13 & 33 \\
\hline Terengganu & 0 & 0 & 0 & 0 & 0 & 0 & 0 & 0 \\
\hline Sabah & 1 & 13 & 1 & 3 & 0 & 0 & 2 & 20 \\
\hline Sarawak & 0 & 30 & 0 & 0 & 0 & 0 & 17 & 47 \\
\hline Total & 7 & 54 & 12 & 4 & 0 & 3 & 32 & 112 \\
\hline
\end{tabular}

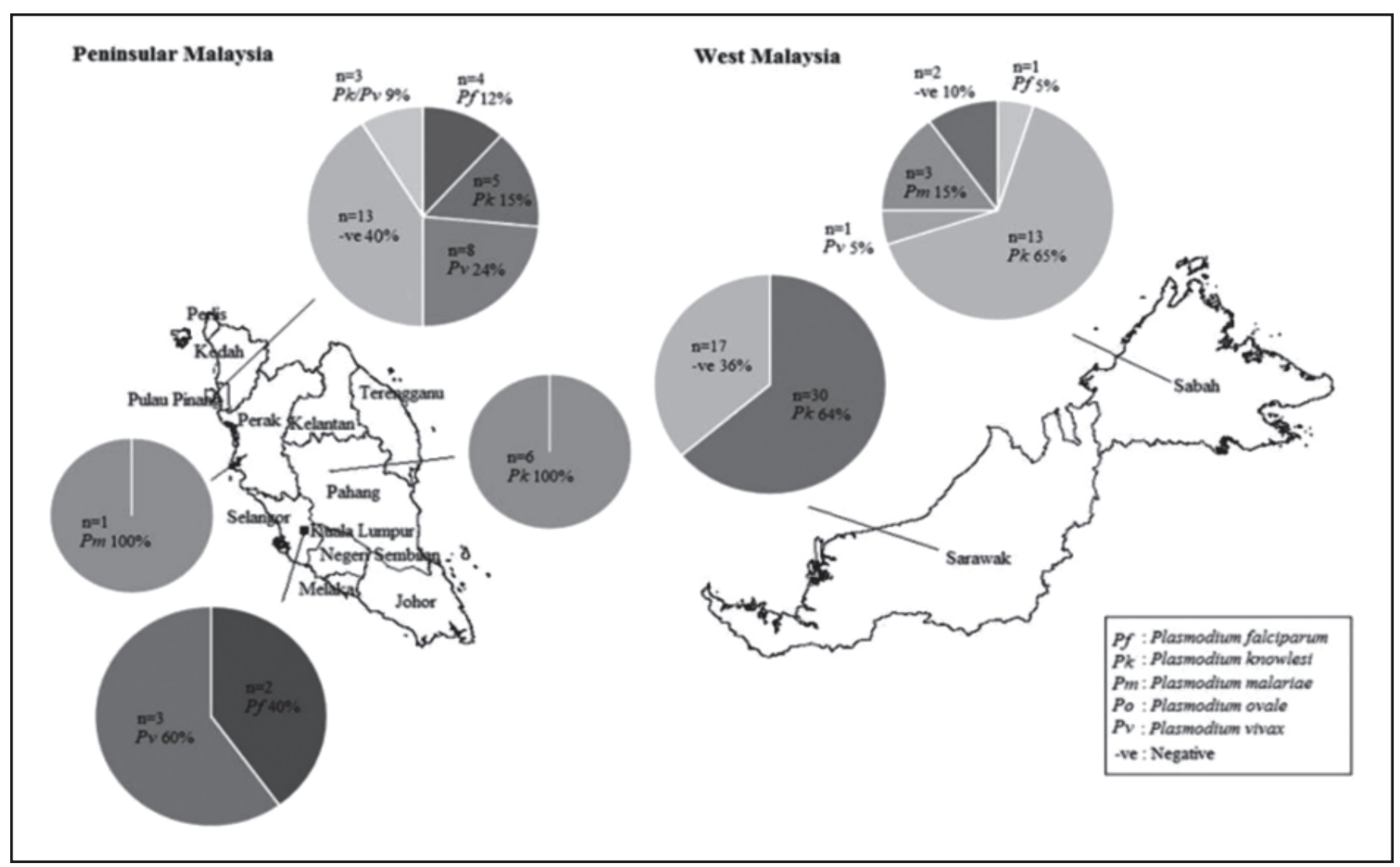

Figure 2. Map of Malaysia showing Plasmodium spp. areas. Pie chart represents the number of cases and percentages of each Plasmodium spp. and negative malaria infections determined by species specific nested PCR.

( $n=2)$, respectively. In Sabah, P. knowlesi, P. vivax, P. falciparum and $P$. malariae were responsible for $11.5 \%(n=13), 0.9 \%(n=1)$, $0.9 \%(n=1)$ and $2.7 \%(n=3)$, respectively. However, no cases were positive for any of the Plasmodium spp. nested PCR assays in Terengganu (Figure 2). Three mixed infections of $P$. knowlesi/ $P$. vivax were also detected in Pulau Pinang. Among the 112 samples, no samples were positive for $P$. ovale nested $P C R$ assays. A total of 32 microscopy positive samples were not detected using nested PCR. Some of the false positive and false negative results were double confirmed with LAMP.

\section{DISCUSSION}

This study highlights the incidence of malaria infections from Kuala Lumpur, Pahang, Perak, Pulau Pinang, Terengganu, Sabah and Sarawak with exclusively attention in $P$. knowlesi malaria. The collected data shows that $P$. knowlesi achieved the highest prevalence among other human malaria Plasmodium spp. with 54 cases (48.2\%) between year 2015 and 2016. In comparison to P. knowlesi infection, a small number of $P$. falciparum ( 7 cases or $6.3 \%$ ) and $P$. vivax (12 cases or $10.7 \%$ ) malaria were obtained from the data collection areas. In 2014, the previous study showed that $P$. falciparum and $P$. vivax malaria in Malaysia were $11 \%$ and $29 \%$, respectively (Yusof et al., 2014). This has coincided with a decline of both cases in Malaysia. Moreover, this trend proved the successful of the malaria eradication program.

From the collected data, 32 cases were not detected by PCR. The patients presented quotidian pattern of febrile illness such as daily fever and chills during the admission to the hospitals. These patients were enrolled in our study as they were microscopy positive for malaria infection. 
Nonetheless, the PCR results screening shown negative for Plasmodium spp. These samples were stored a few months before shipping to the laboratory for further PCR diagnosis. Prolonged storage of the samples while waiting to be sent also contribute to the possibilities of negative PCR results. On top of that, the DNA may be degraded while shipping at room temperature to the laboratory. Shipping over long distance may cause the loss of the DNA quality. Therefore, efficient and reliable transport is crucial to avoid loss in DNA quality of the samples (Straube \& Juen, 2013).

From Table 3, three cases of $P$. knowlesi infection were misdiagnosed as $P$. malariae and 1 as $P$. falciparum by microscopic examination. P. knowlesi was misdiagnosed as $P$. malariae due to their similarities of morphology. Early trophozoites of $P$. knowlesi were similar to $P$. falciparum while other stages were resemble to $P$. malariae (Sulistyaningsih et al., 2010). In fact, macaques are a natural reservoir for $P$. knowlesi and other simian Plasmodium spp.. In Malaysia, researchers begin focus on the investigation of this parasite when human infections on P. knowlesi was largely reported from Kapit, Sarawak in 2004 (Singh et al., 2004). Comprehensively, researchers should pay extensive attention on any potential incidence presenting ' $P$. falciparum-like parasites' and ' $P$. malariae-like' parasites. Misdiagnosed $P$. knowlesi as $P$. falciparum may delay the treatment and potentially caused fatal to the patients due to the rapid replication cycle of $P$. knowlesi.

The present study indicates that $P$. knowlesi was the highest prevalence (55.6\%) in Sarawak. This has been coincided with a previously published report that indicated the highest incidence of $P$. knowlesi malaria from Sarawak as well (Yusof et al., 2014). The finding revealed that $P$. knowlesi has a higher proportion to cause significant public health problems among the populations in Sarawak. The highest incidence of the zoonosis $P$. knowlesi in Sarawak may due to the deforestation and logging activities in certain interior regions. As forest was the natural habitat for macaques, deforestation activities would lead their movement to the areas near housing environment. Thus, the chances of parasites transmissible from macaques to humans via mosquito bites were increased. The $P$. knowlesi which was initially with macaques as the reservoir host may switch to humans as the preferred hosts. Therefore, effective control, prevention and management system is necessary in order to reduce the morbidity and mortality rates among the populations in Sarawak.

Though microscopy is a gold standard for the detection of malaria, our findings suggest that nested PCR is more specific in detection of $P$. knowlesi. Thus, nested PCR was a highly recommended method in diagnosis especially in the detection of samples with mixed infections and low parasitemia as microscopic examination may cause the likelihood of false negative results. Therefore, microscopic alone was not reliably to distinguish $P$. knowlesi from $P$. malariae, $P$. falciparum and $P$. vivax.

In this study, PKF1140 and PKR1550 primer pairs ( $\sim 50 \mathrm{bp}$ ) was used for $P$. knowlesi species-specific diagnosis in nested 2 PCR while the commonly used pmk8 and pmkr9 primer pairs were not used. Imwong et al. (2009) has proved that nonspecific binding was found between $P$. knowlesi and $P$. vivax. Although the forward sequence, pmk8 was highly specific to $P$. knowlesi, the reverse sequence, pmkr9 was found in other Plasmodium spp. especially $P$. vivax S-type strains.

Malaysia has declared its aim to eradicate malaria infection by year 2020. To achieve this compliment effectively, there is necessary to investigate the route of the true transmission of malaria infections. It has been proposed that there were three possible ways of transmission; macaques-human, human-human or human-macaques. Interruption of the transmission pathway is the prerequisite in successfully elimination of malaria. Understanding the risk factors of malaria infections and mosquito vectors may assist in control and elimination of human malaria.

In conclusion, higher levels of $P$. knowlesi infection has challenged the malaria eradication efforts in Malaysia. Among the Plasmodium spp., P. knowlesi caused the highest prevalence of infections, specifically in Sabah and Sarawak. Meanwhile, the highest prevalence of $P$. knowlesi in Peninsular Malaysia was noticeable in Pulau Pinang. To limit the further increase of the $P$. knowlesi infections in Malaysia, it is crucial to implement an effective control and management strategy as well as understanding the malaria vector (Anopheles spp.) behaviour around the malaria endemic areas.

\section{ACKNOWLEDGEMENT}

This study was funded by a Long Term Research Grant Scheme (LR002D-2018, LRGS/1/2018/UM/01/1/4) from the Ministry of Education, Malaysia.

\section{Conflict of interest}

The author declares that they have no conflict of interests.

\section{REFERENCES}

Alemu, A., Shiferaw, Y., Addis, Z., Mathewos, B. \& Birhan, W. (2013). Effect of malaria on HIV/AIDS transmission and progression. Parasites \& Vectors 6: 18. https://doi.org/ 10.1186/1756-3305-6-18

Chin, W., Contacos, P.G., Coatney, G.R. \& Kimball, H.R. (1965). A naturally acquired quotidian-type malaria in man transferable to monkeys. Science 149: 865. https://doi.org/ 10.1126/science.149.3686.865

Foster, D., Cox-Singh, J., Mohamad, D.S., Krishna, S., Chin, P.P. \& Singh, B. (2014). Evaluation of three rapid diagnostic tests for the detection of human infections with Plasmodium knowlesi. Malaria Journal 13: 60. https://doi.org/10.1186/ 1475-2875-13-60

Imwong, M., Tanomsing, N., Pukrittayakamee, S., Day, N.P., White, N.J. \& Snounou, G. (2009). Spurious amplification of a Plasmodium vivax small-subunit RNA gene by use of primers currently used to detect $P$. knowlesi. Journal of Clinical Microbiology 47: 4173-4175. https://doi.org/10.1128/ JCM.00811-09

Jamaiah, I., Rohela, M., Nissapatorn, V., Khoo, B.L., Khoo, P.S., Radhiyah, M. \& Aisyah, A. (2005). Malaria: a 10-year (19942003) retrospective study at University Malaya Medical Center (UMMC), Kuala Lumpur, Malaysia. Southeast Asian Journal of Tropical Medicine \& Public Health 36: 60-63.

Jeffree, S.M., Ahmed, K., Safian, N., Hassan, R., Mihat, O., Lukman, K.A., Shamsudin, S.B. \& Kamaludin, F. (2018). Falciparum malaria outbreak in Sabah linked to an immigrant rubber tapper. American Journal of Tropical Medicine and Hygiene 98: 45-50. https://doi.org/10.4269/ ajtmh.17-0081

Koh, K.H., Chew, P.H. \& Kiyu, A. (2004). A Retrospective Study of Malaria Infections in an intensive care unit of a general hospital in Malaysia. Singapore Medical Journal 45: 28-36. https://doi.org/10.1016/j.jflm.2012.02.030 
Lau, Y.L., Lai, M.Y., Fong, M.Y., Jelip, J. \& Mahmud, R. (2016). Loop-mediated isothermal amplification assay for identification of five human Plasmodium species in Malaysia. American Journal of Tropical Medicine and Hygiene 94: 336-339. https://doi.org/10.4269/ajtmh.15-0569

Pimenta, P.F.P., Orfano, A.S., Bahia, A.C., Duarte, A.P.M., RíosVelásquez, C.M., Melo, F.F., Pessoa, F.A.C., Oliveira, G.A., Campos, K.M.M., Villegas, L.M. et al. (2015). An overview of malaria transmission from the perspective of Amazon Anopheles vectors. Memorias Instituto Oswaldo Cruz 110: 2347. https://doi.org/10.1590/0074-02760140266

Rahman, W.A., Che'Rus, A. \& Ahmad, A.H. (1997). Malaria and anopheles mosquitos in Malaysia. Southeast Asian Journal of Tropical Medicine and Public Health 28: 599-605.

Singh, B. \& Daneshvar, C. (2010). Plasmodium knowlesi malaria in Malaysia. Medical Journal of Malaysia 65: 224-230.

Singh, B., Sung, L.K., Matusop, A., Radhakrishnan, A., Shamsul, S.G., Cox-Singh, J., Thomas, A. \& Conway, D.J. (2004). A large focus of naturally acquired Plasmodium knowlesi infections in human beings. Lancet 363: 1017-1024. https://doi.org/ 10.1016/S0140-6736(04)15836-4

Snounou, G., Viriyakosol, S., Zhu, X.P., Jarra, W., Pinheiro, L., do Rosario, V.E., Thaithong, S. \& Brown, K.N. (1993). High sensitivity of detection of human malaria parasites by the use of nested polymerase chain reaction. Molecular and Biochemistry Parasitology 61: 315-320. https://doi.org/ 10.1016/0166-6851(93)90077-b

Straube, D. \& Juen, A. (2013). Storage and shipping of tissue samples for DNA analyses: A case study on earthworms. European Journal of Soil Biology 57: 13-18. https://doi.org/ 10.1016/j.ejsobi.2013.04.001
Sulistyaningsih, E., Fitri, L.E., Löscher, T. \& Berens-Riha, N. (2010). Diagnostic difficulties with Plasmodium knowlesi infection in humans. Emerging Infectious Disease 16: 10331034. https://doi.org/10.3201/eid1606.100022

Vythilingam, I., Noorazian, Y.M., Huat, T.C., Jiram, A.I., Yusri, Y.M., Azahari, A.H., Ismail, N., Abdullah, N. \& Sulaiman, L.H. (2008). Plasmodium knowlesi in humans, macaques and mosquitoes in peninsular Malaysia. Parasites and Vectors 1: 26. https://doi.org/10.1186/1756-3305-1-26

Warhurst, D.C. \& Williams, J.E. (1996). Laboratory diagnosis of malaria. Journal of Clinical Pathology 49: 533-538. https:/ /doi.org/10.1136/jcp.49.7.533

William, T., Rahman, H.A., Jelip, J., Ibrahim, M.Y., Menon, J., Grigg, M.J., Yeo, T.W., Anstey, N.M. \& Barber, B.E. (2013). Increasing incidence of Plasmodium knowlesi malaria following control of $P$. falciparum and $P$. vivax Malaria in Sabah, Malaysia. PLoS Neglected Tropical Diseases 7: e2026. https://doi.org/10.1371/journal.pntd.0002026

World Health Organization. (2018). World Malaria Report: 2018. Geneva, Switzerland: World Health Organization.

Yusof, R., Lau, Y., Mahmud, R., Fong, M., Jelip, J., Ngian, H., Mustakim, S., Hussin, H.M., Marzuki, N. \& Ali, M.M. (2014). High proportion of knowlesi malaria in recent malaria cases in Malaysia. Malaria Journal 13: 168. https://doi.org/ 10.1186/1475-2875-13-168 